\title{
VIRTUAL ENVIRONMENT FOR THE DEVELOPMENT OF THE SKILLS OF THE STUDENTS IN THE GARMENT INDUSTRY
}

\author{
Nour Abdel Hadi AL-SUBAYANI*
}

Faculty of Home Economics, King Abdul-Aziz University

\begin{abstract}
The objective of the research is to plan a virtual environment and determine how effective it is to develop the skills of female students in the garment industry by providing them with the knowledge and skills of the garment industry, as well as identifying the basic requirements for building virtual learning environments in higher education institutions. The research sample consisted of (15) female students of the Faculty of Home Economics at King Abdul-Aziz University. The research tools were:

A virtual learning environment for developing the skills offemale students in the garment industry.

A questionnaire listing the actual needs for building a virtual learning environment.

Achievement test (Pre/ post) to measure the knowledge contained in the virtual environment.

Practical application test (pre/ post) to measure the skills involved in the virtual environment.

Note card to evaluate the results of the students to measure the skills contained in the virtual environment.

Keywords

Virtual Environment, Garment Industry, Virtual Learning Environments, Clothing and Textiles.
\end{abstract}

\section{Introduction}

The modern era is witnessing a scientific revolution and an explosion of knowledge, science and technology, where the accumulation of statements and theories, and technological applications in a way never seen before in this era of information, which carries many changes in all aspects of life, as a result of these changes, it was necessary to respond to them through the development of all the institutions of the society through the use of technological innovations in them. The institutions of education in any society are the first to develop in order to cope with the nature of the age and to respond to the transformations that encompass different areas of life (Assaid, 2005).

Especially that it can be said that the general goal of educational institutions and the educational process is to produce students with rich information, rich knowledge, characterized by an organized memory, and valuable ideas, and have different scientific skills to employ them in the service of themselves and serve their community, and through quality education, good quality of education is provided, and through the provision of quality education, society is developed and flourished (Darwaza, 2000).

In order for the education process to be effective, attention must be paid to the two aspects of the communication process (teacher and student). As a follower of educational thought, 
traditional education focused on the teacher and made him the main element in the educational process, as he was responsible for teaching the learners without considering their abilities and readiness (Assaid, 2005). It can be said that the student does not learn what he does not understand, especially if it is necessary to use his thinking in criticism, analysis, conclusion and other mental skills, and this is evident in the investigations that require such skills as science researchers where Al- Omaria (2004) indicates that the student does not learn what he does not understand, and if the student memorize something he doesn't understand he will forget it immediately. Science education must be based on a conscious understanding of everything taught in scientific content (Al-Omaria, 2004).

Hence, there is a difficult equation that needs to change education systems and teaching strategy so that we can achieve the goals of education. One of the most important things we need to achieve this change is to follow the method of self- learning, while providing multiple learning methods for both students and teachers (Sharaf al-Din, 2000).

Piaget believes that education is not easy. It needs planning and understanding the concepts that a student can study at a certain age, thus creating and identifying the activities he can do, and allowing himself to discover the information and focus in the teaching process on experimentation and exploration, not indoctrination And Conservation (Zeitoon, 2002).

Modern virtual learning environments and their multimedia content are an effective alternative to verbal presentations (i.e., using images and words together). Recent developments in communication and graphic technologies have stimulated efforts to recognize the potential of using multimedia as a means of enhancing human understanding (Mayer, 2001), Nabelsi, 2004) These multimedia-based technologies (Virtual Learning Environments) have proven to be effective in teaching various disciplines, including natural science. This detective, which most students and teachers have learned, is not easy (Shaqour, 2007), where interactivity in multimedia represents the great democratic victory of informatics so that the machine can respond to us and achieve our desires, and the form of interaction depends on the type of medium (Enola, 2004).

Research Goals:

1- Planning a virtual environment for developing the skills of female students in the garment industry.

2- Determine the effectiveness of the virtual environment to develop the skills of female students in the garment industry by providing them with the knowledge and skills of the garment industry.

3- Identify the basic requirements for building virtual learning environments in higher 
education institutions.

Significance of the Study:

1- Developing the knowledge and skills of female students to cope with the rapid technological development in the garment industry.

2- The research is a new addition in the garment industry through the transfer of traditional learning materials to the virtual learning environment.

3- The results of this research may contribute to providing institutions of higher education with a list of needs and requirements when starting to build virtual learning environments.

Terms of the study:

Virtual Environment: A set of software that provides programs and curricula electronically via computer and the Internet. This software provides a range of teaching tools aimed at serving students and teachers and enhancing the learning process (Michale Inola 2004).

The virtual environment in this search is:

Group of processes related to the transfer and delivery of different types of knowledge to learners around the world using information technology.

Development: A process of social change planned to move the society to a better situation in line with its needs and economic and social potential (Al-Kallini: 2007).

Skill: A group of individual's consistent responses that develop by learning and practice until they reach a high level of perfection (Zaitoun: 2005).

What is meant by skill in this research is:

- The performance of students in the skills of the garment industry through the virtual learning environment.

Industry: The craft of the manufacturer, which is all science or art practiced by man until he becomes proficient in it and becomes a craft for him (compound Arabic language: 2003 )

Clothes Industry: Are the processes through which raw materials are produced for production since they were fabrics until they become finished garments and are ready for consumption during their production processes (cutting, knitting, ironing) (Zeinab Abdel Hafeez: 2006: 15). Research hypotheses

1- There are statistically significant differences between the mean scores of students in the virtual environment before and after application in favor of the post application.

2- There are statistically significant differences between the average scores of students in the knowledge acquired before and after the application for the post-test, and under this hypothesis fall the following sub-hypotheses:

2-a: There are statistically significant differences between the average scores of students in the 
acquired knowledge of intermingling models before and after application in favor of post-test. 2-b: There are statistically significant differences between the average grades of students in the acquired knowledge of the layers of cloth before and after application in favor of the post-test. 2-c: There are statistically significant differences between the average grades of students in the acquired knowledge of cloth cutting before and after application in favor of the post-test.

3- There are statistically significant differences between the average grades of students in the skills acquired before and after the application in favor of the post-test, and under this hypothesis fall the following sub-hypotheses:

3-a: There are statistically significant differences between the average scores of students in the skills acquired for the interlock of models before and after application in favor of the post-test. 3-b: There are statistically significant differences between the average grades of students in the acquired skills of the cloth layers before and after the application in favor of the post-test.

3-c: There are statistically significant differences between the average grades of students in the skills acquired for cutting cloth before and after application for the post-test.

Previous Studies

The researcher reviewed some studies in the field of virtual learning environments such as: Shaqour (2007) conducted a study on the level of assessment of teachers and science teachers in UNRWA schools in the Governorate of Nablus for virtual laboratories simulating reality in the educational process and this study tried to answer the following questions:

- What is the level of assessment of teachers and science teachers in UNRWA schools in Nablus governorate for virtual laboratories simulating reality in the educational process?

- $\quad$ Are there differences in the level of assessment of teachers of science in UNRWA schools in Nablus Governorate for virtual laboratories simulating reality in the educational process due to gender?

- $\quad$ Are there differences in the level of assessment of science teachers in UNRWA schools in Nablus Governorate for virtual laboratories simulating reality in the educational process due to the number of years of experience?

- $\quad$ Are there differences in the level of assessment of science teachers in UNRWA schools in Nablus Governorate for virtual laboratories simulating reality in the educational process due to scientific qualifications?

- $\quad$ Are there differences in the response of the study sample members on the dimensions of the level of assessment of teachers of science in UNRWA schools in Nablus governorate for virtual laboratories simulating reality in the educational process?

Where the study was limited to teachers who teach science in UNRWA schools in Nablus for 
the academic year 2006/2007, the sample of the study consisted of (51) teachers, the validity of the questionnaire has been verified through a number of arbitrators and take their views and observations, For statistical processing, the statistical processing program (SPSS) was used, and the mean, the standard deviations, were calculated for the questionnaire paragraphs as well as their percentages.

- The results of the study showed that:

- The assessment of teachers for virtual laboratories was generally high and did not reach very high because of their low assessment of the potential of these laboratories, which were of a medium grade. Their evaluation of curriculum and management was high. As for their assessment of both teacher and learner, it reached a very high degree. Thus, there was a significant difference in their assessment of these dimensions.

- The paragraph on the role of virtual laboratories to solve all problems in teaching science ranked lowest among the paragraphs of this axis at an average of (6.3), but it was high and thus concluded that such laboratories can help solve certain problems in teaching science.

- As for the student's axes, the paragraph related to the development of their attitudes towards scientific research when using such laboratories has reached the highest level. While the paragraph related to the assistance of these laboratories in the evaluation of learners among the lowest levels of the level because of the nature of these laboratories, which depends on problem solving, exploration and analysis more than the evaluation of the performance of students.

- Regarding the axis of potential, the answer to the paragraph concerning the need to equip the laboratory of science with computers was very high and this indicates the need to provide these equipments.

- Despite the high level of teachers' assessment of these laboratories, they do not see them as a substitute for real laboratories.

- The evaluation of male respondents was the highest level of female evaluation in the post-student period, and this may be due to the knowledge and potential available to males in this field.

- For post-potential, the assessment was highly high for teachers with more years of experience.

- There were no statistically significant differences for the scientific qualification indicating that the evaluation process for this type of technology is not affected among the holders of one specialization according to the different scientific qualifications In the light of these results, the researcher came out with a set of recommendations and 
proposals, including:

- $\quad$ Encourage designers of computer education programs to develop programs of virtual learning environments in Arabic, as the language of instruction in these schools is Arabic.

- $\quad$ Conduct studies on the role of these virtual environments and their contribution to achievement.

Jabr (2007) examined the effect of using computer on the achievement of seventh grade students in mathematics and the attitudes of their teachers towards using it as an educational tool, it also aimed to investigate the impact of using computer on the achievement of the seventh grade students in mathematics, compared to the traditional method, and to know the attitudes of their teachers towards using it as an educational tool.

The study population consists of all seventh grade students in the Salfit schools in the academic year 2007/2006. The study population included all 37 teachers in the seventh grade in mathematics.

The sample of the study was (94) male and female students of the seventh grade in the governorate in 2006-2007, and the number of teachers (37 teachers), All mathematics teachers of the grade in the province to study their attitudes towards the use of computers as an educational tool.

This study attempted to answer the following questions:

1- The impact of computer use in teaching mathematics on the achievement of seventh grade students Core group unit?

2- The attitudes of mathematics teachers towards the use of computers as an educational method in teaching Mathematics?

To answer the study question, the researcher used a computerized program that was developed using the Point Power program, applied the study tools to the sample, collected the data and analyzed it using the statistical SPSS package, and used

the analysis of the single variance to verify the parity of the groups in the tribal test, to find out the effect of the variables of the method of teaching and sex and the interaction between them on the achievement in the post-test, and the Toki-Kramer test of the post-comparisons between the study groups, the most important findings of the researcher include the following:

There were statistically significant differences at the level of significance $(\alpha=05.0)$ between the averages of the achievement of the seventh grade students in the post-measurement in the unit of mathematics due to the method of teaching (computer, traditional) and in favor of the method of teaching the computer. The study did not reveal statistically significant 
differences Gender or interaction between teaching strategy and gender.

- $\quad$ There are positive attitudes among mathematics teachers of the seventh grade towards the use of computers as an educational tool in the teaching of mathematics.

Stewart, et al. (2006) conducted a study entitled "Virtual Technology and Education", the aim of this study was to explore the effect of using a collaborative team consisting of a virtual course developed by the researcher to increase the educational experience of the students. While students continue to engage in recreational video game activities and others, and integrating such applications into their learning environments becomes important to allow them to communicate and interact with the content of the course in the way they are accustomed to in their daily lives.

The study was conducted at the University of Houston, the third comprehensive research university in Texas, where a virtual course component was developed to increase educational experience in a course of online public education in the Human Development and Consumer Sciences (HDCS). This chapter presents a beginner class as a prerequisite for general university education for the separation of sociology and this chapter is (1300HDCS). This course is offered at the College of Technology but is available to all undergraduate students in any department within the University. The primary goal of embedding the default component in the 1300 HDCS online course was to create an environment that emphasizes learning through a high level of student participation. The sample consisted of 46 students who participated in the pilot test. The study showed the following results:

- Virtualization can be used to engage students and activate them in a new way

- Give the collaborative team the opportunity to explore new ways and thus provide incentives for teaching and learning.

- In this study, students were encouraged to participate in multiple ways to explore a number of topics and applications.

Finally, the study gave suggestions for other applications of the virtual environment, for example in companies because of the possibility of learning before converting easily to real and actual work.

Coxjr, et al. (2006) conducted a study entitled "Assessing Student Understanding with Technology". The study aimed to identify the effectiveness of using an IMUMEX website to solve students' scientific knowledge problems. The problem of the study was that most of the science teachers in the knowledge and analysis of the causes of weakness and error of their students when the tests, especially with the lack of time to analyze the problem, which made this problem difficult and challenging teachers face even when they provide written 
justification.

The results of the study showed the following:

- This study showed that students are now presenting their subjects in the space problem, and they considered that it is necessary to put the issues within specific frameworks to determine which information has relevance and which is not related to these issues.

- $\quad$ The strategy of student interaction with this site varied from stage to stage.

- $\quad$ This method allows researchers to determine how students behave at different stages of the solution, and thus it is possible to design appropriate strategies to solve the problems and issues facing them. It also helps educators to review their previous strategies, identify students' needs, meet them and identify their faults.

This method was characterized by the fact that the time to analyze students' outcomes and weaknesses constitutes a small fraction of the time required by traditional means.

- In addition to providing an accurate description of each student's situation, IMMEX also provides us with analysis and information for the class as a whole, helping to identify the needs of these classes.

Although studies on virtual learning environments have varied in different areas of education, there has been a paucity of studies on virtual learning environments in the garment industry.

The use of virtual learning environments gives more flexibility to university education, and there is a possibility to adapt these environments in the light of the educational and educational goals sought by university education. Educational problems require the need to search for formulas and technological methods that contribute to overcome them and meet the educational needs and benefit from technological innovations and employ them in different learning environments to take into account learners' needs, nature and circumstances.

As a result of this trend by the state and educational institutions, the researcher has planned a virtual environment for developing the skills of female students in the garment industry.

Methodology of the Study: Research Approach:

This research followed the experimental approach to suit the objectives of the research and verification of its hypotheses

\section{Sample of the Study:}

The study was applied to (15) students of the Faculty of Home Economics, King Abdul-Aziz University.

\section{Research tools}

1- A virtual learning environment for developing the skills of female students in the garment industry. 
A questionnaire listing the actual needs for building a virtual learning environment.

1- Achievement test (Pre / post) to measure the knowledge contained in the virtual environment.

2- Practical application test (pre / post) to measure the skills involved in the virtual environment.

3- $\quad$ Note card to evaluate the results of the students to measure the skills contained in the virtual environment.

\section{Research limits:}

- $\quad$ Interlock models.

- $\quad$ Tighten the cloth layers.

- $\quad$ Cut cloth layers.

\section{Validity and Reliability of the tools Validity of the questionnaire}

Validity was calculated using internal consistency by calculating the correlation coefficient (Pearson correlation coefficient) between the total score of each axis and the total score of the questionnaire. The following table illustrates this:

\section{Research Recommendations}

1- Designing alternative virtual learning environments for traditional learning.

2- $\quad$ Planning virtual environments for other courses in clothing and textiles.

3- Take advantage of regional and global experiences of virtual learning environments in higher education institutions.

\section{References}

1- Al-Kallini, S. (2007) Media and Development, Dar Al-Nahda Al- Arabiya, Cairo

2- Al-Omaria, S. (2005) "Teaching Methods of Science". Arab Society Library for Publishing, Amman Jordan.

3- $\quad$ Assaid, A. (2005) "Educationaltechnology and teaching aids". Dar Al - Israa Printing Press, Tanta. Egypt.

4- Darwaza, A. (2000) "EducationalQuestions and School Assessment"Vol,3., Nablus, Palestine

5- Enola, M. (2004) Multimedia and its Applications in Media, Culture and Education, Nasr Eddine Al-Ayadi, Dar al-Wa'ab al-Jami', United Arab Emirates

6- Jabr, W. (2007) "The impact of usingcomputer on the achievement of seventhgrade students in mathematics and their teachers' attitudes toward its use as an educational tool" Unpublished MA thesis, Graduate School of Economics, An-Najah National University, Nablus, Palestine 
7- Shaqour, A. (2007) "Assessment of Teachers and Science Teachers in UNRWA Schools in Nablus Governorate for Virtual Labs Simulating Reality in the Educational Process", Unpublished Research, Al-NajahUniversity, Nablus, Palestine.

8- $\quad$ Stewart, Barbara L., Ezell, Shirly, DeMartino Darrell, Rifai, Rana\& , Gatterson, Beverly (2006)."VIRTUAL TECHONOLGY And EDUCATION A COLLABORATIVE PILOT CASE"

.The Quarterly Review of Distance Education Vol.7,No,4. pp.377-385

9- The Arabic Language Complex: The Wajeez Dictionary, General Authority ofEmiri Printing Press, 2003.

10- Zainab Abdel Hafiz Farghaly: Ready- made garments between preparation and production, Dar Al-Fikr Al-Arabi, second edition, 2006.

11- Zeitoun, H. (2005) the Design of Teaching Systemic Vision, "The Series of Origins of Teaching", Volume Two, Volume 1, World of Books, Cairo.

12-Sylvia ESSER, REFORMULATION OF INTERCULTURAL COMPETENCE IN THE CONTEXT OF A DIVERSITY-CONSCIOUS TEACHER EDUCATION AND PEDAGOGICAL SCHOOL DEVELOPMENT, International Journal of Creativity and Innovation in Humanities and Education, Vol. 2 No. 2, 2019, pp. 10-13.

13-Salwa Mahmoud HANAFY, PLASTIC VISION FOR TEACHING METAL WORKS, International Journal of Creativity and Innovation in Humanities and Education, Vol. 2 No. 2, 2019, pp. 14-16

Received: February 12, 2020

Accepted: April 25, 2020 